\title{
PRECISE FORMULA FOR VOLUME COMPUTATIONS USING CONTOURS METHOD
}

Fórmula precisa para cálculo de volumes utilizando o método das curvas

E. Napoles ${ }^{1}$ - ORCID: 0000-0001-8736-1009

M. Berber ${ }^{1}$ - ORCID: 0000-0002-2983-109X

${ }^{1}$ Department of Civil and Geomatics Engineering, California State University, Fresno, CA, USA E-mail: ednaps@mail.fresnostate.edu; muberber@csufresno.edu

Received in January $15^{\text {th }}, 2017$.

Accepted in July $3^{\text {rd }}, 2017$.

\section{Abstract:}

Except some special cases, commonly used volume computation methods are grids method, contours method and volume computations by utilizing TIN (Triangulated Irregular Network). In this study, to investigate the precisions of these techniques, a grid system is established in an undulating area and volume of the mound is determined by using these three volume computation methods. It is found out that contour method results were not as price as the other two methods. Thus, a precise formula for volume computations using contours method is proposed.

Keywords: Volume computations; Grids method; Contours method; Triangulated Irregular Network.

\section{Resumo:}

Exceto em alguns casos especiais, os métodos de cálculo de volume utilizam grids, curvas de nível e volume, por meio de TIN (Triangulated Irregular Network). Neste estudo, para avaliar a precisão destes métodos, um sistema de grid foi estabelecido em uma área e o volume foi calculado utilizando as três formas citadas. Concluiu-se que o método das curvas não obteve resultados tão bons quanto os demais. Assim, propõe-se uma fórmula precisa para cálculo de volume utilizando as curvas.

Palavras-chave: Cálculo de volumes; Método de grid; Método das Curvas; Triangulated Irregular Network.

How to cite this article: Napoles, E; Berber, M. Precise formula for volume computations Using contours method Bulletin of Geodetic Sciences, Vol. 24, issue 1, 18-27, Jan-Mar, 2018. 


\section{Introduction}

In route and construction surveying projects, to determine the quantity of materials to be moved, volumes are calculated (Kavanagh, 2009; Kavanagh, 2010; Nathanson et al., 2011 and McCormac et al., 2013). There are three commonly used volume computation methods: contours method, grids method and volume computations by utilizing a TIN (Triangulated Irregular Network) surface. If the topographic map of a project area is available, volumes by contour areas can be used for quick estimates. Alternatively, if site conditions permit, a grid system is laid out and the elevations of all grid corners are determined using precise leveling. By using the size of all grids and elevation information, the volume of each grid cell is determined. The total site volume is then calculated by adding the individual values of each cell. Lastly, having imported coordinate and elevation data into a CAD software, a TIN surface can be created that will pass through the project area before and after the excavations and the volume between these two surfaces is computed.

In any method that is used, the intervals between gridlines, or the contour intervals, are important for accuracy. This is because the greater the distance between gridlines, the less the accuracy of the volumes that are computed (Crawford, 2008). There is a tradeoff though, because the smaller the intervals are between gridlines, the longer the time spent in the project site will be. This means maintaining the equipment and personnel out in the field, which automatically translates to increased project costs. Additionally, one may be limited by a certain degree with smaller grid sizes, because if grid sizes are too small it is not possible to take the measurements; for instance, imagine a site covered with wooden stakes set less than a foot from each other. On the other hand, accurate determination of the volume to be moved is critical to the client and the contractor in order for the correct payment to be made. In other words, it is up to the engineer to decide on what approach to use that will yield the maximum accuracy within the minimum time frame.

As mentioned above, depending on the size of the grid used, the grid method is to produce the most accurate results. As long as the triangulated point coordinates and elevations are correct and these points depict the site topography adequately, the TIN method should produce reliable results as well. Yet, to this date and to our knowledge, the precision of the contours method has not been thoroughly investigated. Therefore, in this study, a grid system is established in an undulating area and the volume of a mound is determined by using the contours method, grids method and TIN method and the results are compared.

\section{Methods}

The best method to use depends on the specific project conditions where the volume is to be determined, and on the measurement information available. The engineer must analyze the situation and select the method that will yield the most accurate results in the shortest time (Crawford, 2008). 


\subsection{Contours Method}

If volumes are needed quickly, and the only information that is available consists of contours from a topographic map, the method of contours can be used. This involves identifying on a topographic map the area that will be cut or filled, and determining the area of the contour that will be enclosed. The area of each contour that will be covered will need to be determined. To obtain the volume, the areas of adjacent contours are averaged and multiplied but the contour interval (Crawford, 2008).

Volume $=\mathrm{C}\left(\frac{\mathrm{A}_{1}+\mathrm{A}_{2}}{2}\right)$

where $C$ is the contour interval, $A_{1}$ is the area enclosed by one contour and $A_{2}$ is the area enclosed by the next contour. As shown in section 3 , this is an approximation not a precise approach.

\subsection{Grids Method}

In this method, the area to be covered is staked in squares with the choice depending on project size and accuracy desired (Wolf and Ghilani, 2006). Next, the grid is laid out using a total station or a measuring tape. And then, elevations are determined at all grid intersection points. For this purpose, and for precise work, differential leveling is required. For relatively less precise work, trigonometric leveling may be employed.

Volume $=\mathrm{A}\left(\frac{\mathrm{h}_{1}+\mathrm{h}_{2}+\mathrm{h}_{3}+\mathrm{h}_{4}}{4}\right)$

where $A$ is the area of the grid, $h_{1}, h_{2}, h_{3}$ and $h_{4}$ are the elevations of the four corners of the grid.

\subsection{Triangulated Irregular Network (TIN)}

A TIN surface comprises the triangles that form a triangulated irregular network. TIN lines form the triangles that make up the surface triangulation. To create TIN lines, software such as AutoCAD Civil 3D is required to connect the surface points that are closest together. The elevation of any point in the surface is defined by interpolating the elevations of the vertices of the triangles that the point lies in (Autodesk, 2015). TIN surfaces are passed through the points surveyed before and after the excavations and the volume between these two surfaces is computed by the software. These computations basically follow prismoidal volume computations (see Wolf and Ghilani, 2006; Crawford, 2008; Kavanagh, 2009; Kavanagh, 2010; Nathanson et al., 2011 and McCormac et al., 2013). 


\section{Applications and Results}

Our project area is located on the east side of the Arts Building on the CSU (California State University) Fresno campus (see Figure 1). The mound and the surrounding area were considered for this project. Therefore, a $24.688 \mathrm{~m}(81 \mathrm{ft})$ by $35.662 \mathrm{~m}(117 \mathrm{ft})$ area was staked encompassing the mound. The grid size of $0.914 \mathrm{~m}(3 \mathrm{ft})$ was chosen since generally in practice a $1 \mathrm{~m}$ grid size is used. As a result, 1053 points needed to be marked on the ground using stakes, flags or paint. Under the circumstances, to accelerate the process, points were located on the ground using a total station and the elevations of grid corners were surveyed utilizing differential leveling immediately after locating the point with the total station. For reference to our elevation, a local point (BM ED - see Figure 1) on the west side of the project site was established on a concrete slab with an elevation of $30.480 \mathrm{~m}(100 \mathrm{ft})$.

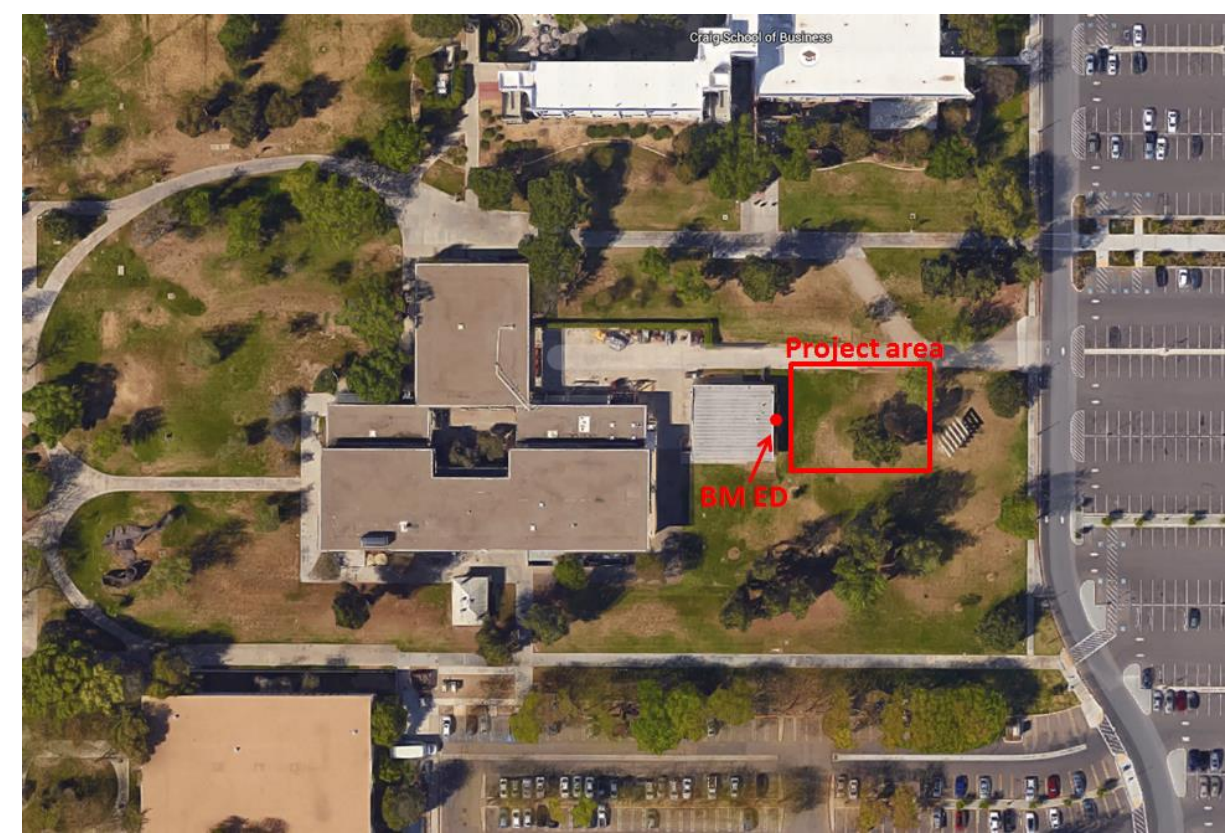

Figure 1. Aerial view of the project site (image from Google).

Once the perimeter of the project site was staked, a total station was set up over the stakes along the northern line and the corners which were the farthest were sighted as backsights. The instrument was then turned $90^{\circ}$ to obtain the line of sight to lay out the grid intersections (see Figure 2). As soon as the point was located using the total station and the reflector pole, the reflector pole was removed and a leveling rod was held at the very same point for differential leveling readings (see Figure 3). For the differential leveling, BM ED was sighted as our backsight and all the grid points were sighted as site shots and the leveling circuits always closed on BM ED for checking purposes. 


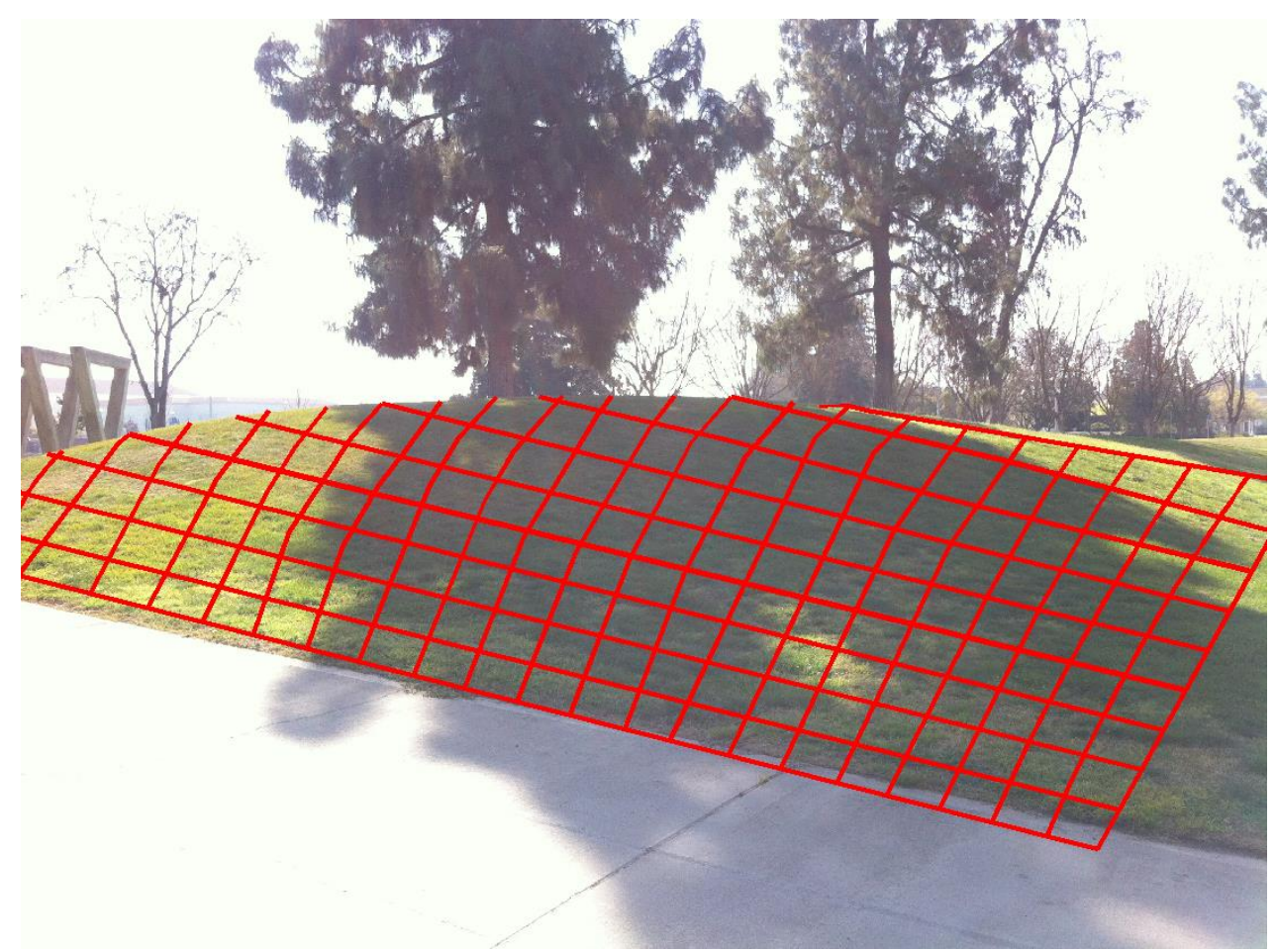

Figure 2. Grid system laid out on the project site. Northern line of the grided area is labeled from " $A$ " to "NN" and the western line is labeled from 1 to 27.

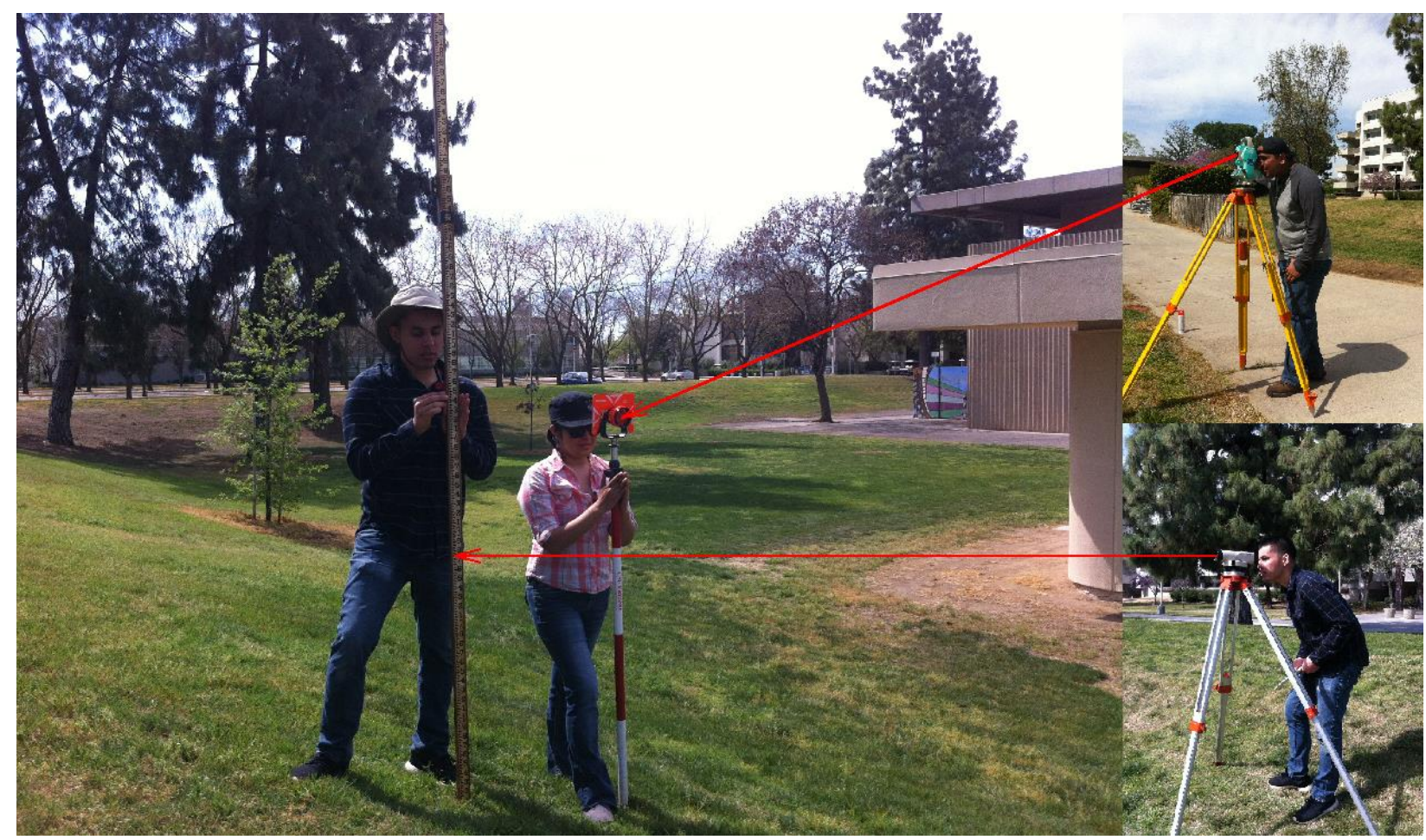

Figure 3. Total station and differential leveling measurements.

At the end of the field work, all data was entered into AutoCAD Civil 3D and drawings and contours were generated (see Figure 4). 


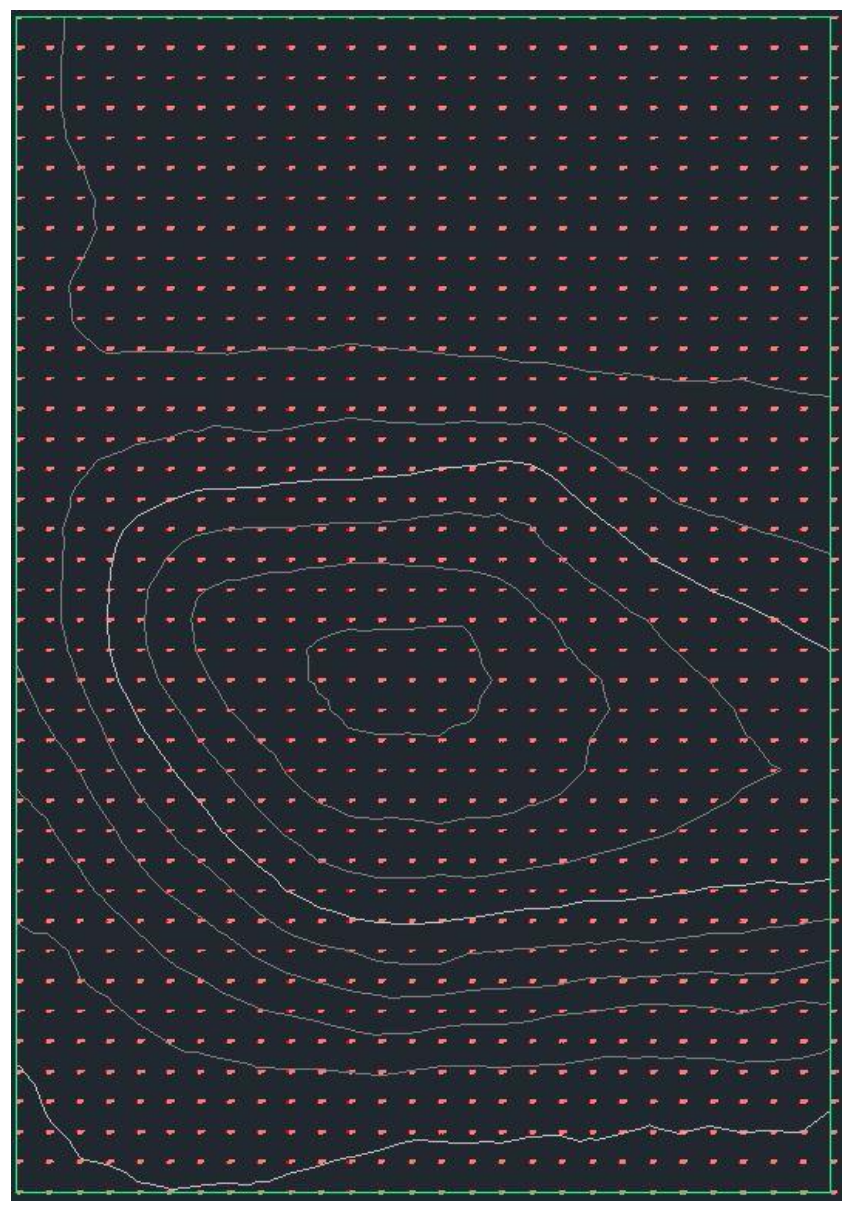

Figure 4. Entire project area with contours.

With the first approach, the area between lines "I" and "AA" was considered since this is the area which has the closed contours (see Figure 5).

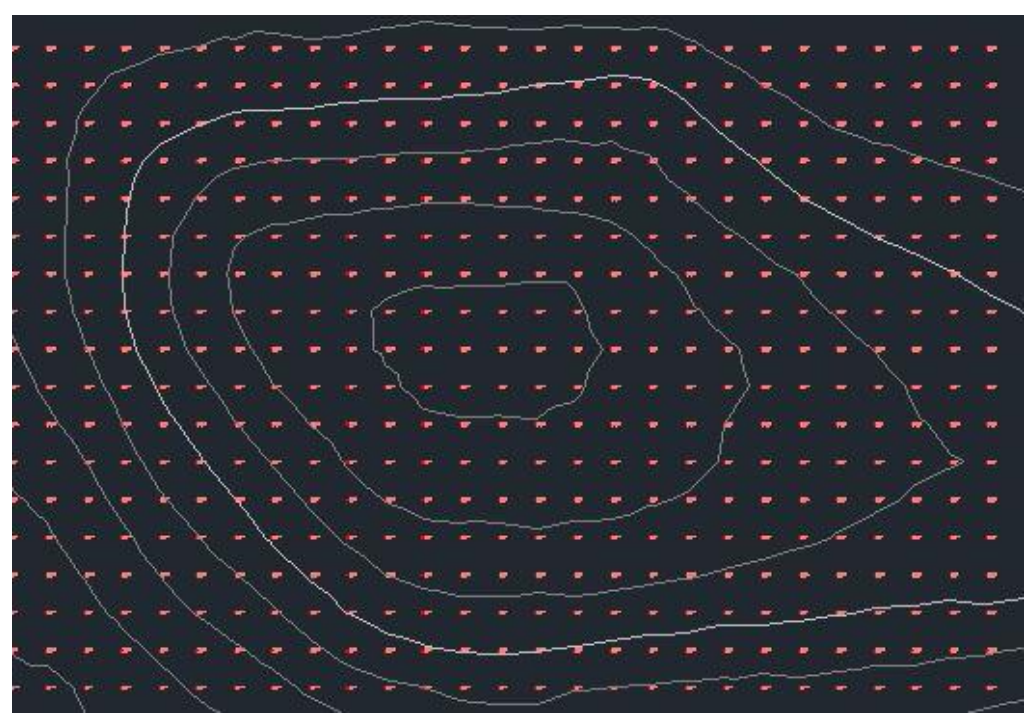

Figure 5. AutoCAD image of the closed contours.

Grid cell volumes were computed by averaging the four corner elevations and by multiplying the mean elevation with $2.743 \mathrm{~m}(9 \mathrm{ft})$ because the size of each grid cell was $0.914 \times 0.914 \mathrm{~m}(3 \times 3 \mathrm{ft})$. In the end, all the cell volumes were summed and the volume from $30.730 \mathrm{~m}(100.82 \mathrm{ft})$ and up 
was determined. $30.730 \mathrm{~m}$ is the lowest elevation between lines "I" and "AA" which was the study area of interest with this first approach. The areas of contours within this frame were also determined using AutoCAD and the volume of the area between contour lines $31.699 \mathrm{~m} \mathrm{(104 \textrm {ft } )}$

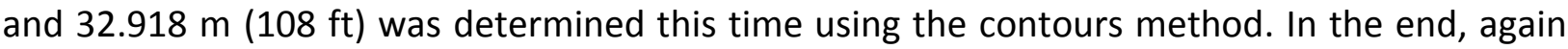
using AutoCAD, a TIN surface was passed through the lowest elevation and another surface was passed through the grid intersections within this area (between $30.730 \mathrm{~m}$ which is the lowest elevation and the top surface described by the grid intersections) and a volume was computed. These results are listed in Table 1, column 2.

With the second approach, the area between lines " $A$ " and " $R$ " was considered since this is the area which has some steep and a gently rolling surface (see Figure 6). The eastern side of the project area was not suitable for these computations since there was not any closed contour.

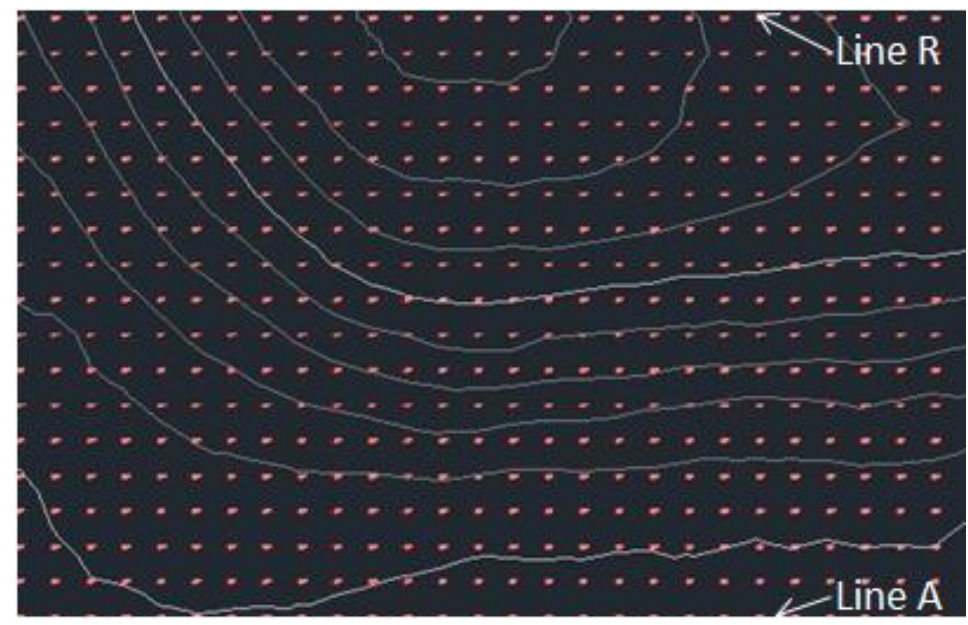

Figure 6. AutoCAD image of the western part of the project area.

Grid cell volumes were computed by following the same guidelines described in the first

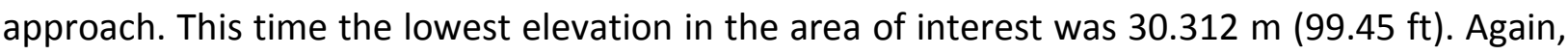
the areas of contours were determined using AutoCAD and the volume of the area between contour lines $30.480 \mathrm{~m}(100 \mathrm{ft})$ and $32.918 \mathrm{~m}$ (108ft) was determined using the contours method. Also, by creating TIN surfaces in AutoCAD the volume was computed. These results are listed in Table 1, column 3.

Table 1. Results of volume computations $\left(\mathrm{m}^{3}\right)$.

\begin{tabular}{ccc}
\hline Method & Approach I & Approach II \\
\hline Grids & 564.714 & 457.777 \\
TIN & 564.392 & 456.565 \\
Contours & 192.116 & 394.733 \\
\hline
\end{tabular}

As can be seen in Table 1, the grid and TIN method results are quite close to each other; nonetheless, the contours method results are rather different. This is because with the grids method and TIN computations, the volume of the entire area of interest is calculated. On the other hand, with the contours method only the volume between the bottom and top contours are determined i.e., the areas below the lowest contour and above the highest contour are not taken into account. Generally, clients demand to know the total volume of the entire project area not just the volume between the bottom and top contours. As a consequence, better volume 
computations using the contours method is needed. For this purpose, authors propose to use the following formula:

$$
\mathrm{V}=\frac{\mathrm{EAI}^{-\mathrm{A}_{1}}}{2}(\mathrm{EBC}-\mathrm{LE})+\sum_{i=1}^{n} \frac{\mathrm{A}_{i}+\mathrm{A}_{i+1}}{2} \mathrm{C}+\frac{\mathrm{A}_{n}}{2}(\mathrm{HE}-\mathrm{EHC})
$$

where EAI is the size of the entire area of interest, $A_{1}$ is the area of the first (bottom contour), $E B C$ is the elevation of the bottom contour, $L E$ is the lowest elevation in the area of interest, $n$ is the number of contours, $\mathrm{C}$ is the contour interval, $\mathrm{HE}$ is the highest elevation and $\mathrm{EHC}$ is the elevation of the highest contour. Using this formula the results in Table 1 are regenerated and the final results are listed in Table 2.

Table 2. Results of volume computations using Eq. (3) $\left(\mathrm{m}^{3}\right)$.

\begin{tabular}{ccc}
\hline Method & Approach I & Approach II \\
\hline Grids & 564.714 & 457.777 \\
TIN & 564.392 & 456.565 \\
Contours & 544.256 & 456.593 \\
\hline
\end{tabular}

Obviously, there is no change with regards to the grid method and TIN volume computations since Eq. (3) is developed for the contours method only. In order to be able to verify the formula, between the highest contour and the points above this contour, 10 more contours are created to pass through. The purpose of doing so is to obtain precise volume information for the area above the highest contour. The results of this approach are given in Table 3.

Table 3. Results of volume computations by passing 10 more contours between the highest contour and the points above this contour $\left(\mathrm{m}^{3}\right)$.

\begin{tabular}{lcc}
\hline Method & Approach I & Approach II \\
\hline Grids & 564.714 & 457.777 \\
TIN & 564.392 & 456.565 \\
Contours & 544.181 & 456.545 \\
\hline
\end{tabular}

To increase the precision, the number of the contours passed between the highest contour and the points above this contour would have to be increased; yet, in the original approach the contour interval was $0.305 \mathrm{~m}(1 \mathrm{ft})$. By passing 10 more contours the contour interval went down to $0.03 \mathrm{~m}(0.1 \mathrm{ft})$ which is almost the attainable precision of a topographic survey. If we compare the results in Tables 2 and 3, we see that the results for the contours method vary 0.075 and $0.048 \mathrm{~m}^{3}$ respectively. This variation is due to the last term in the right hand side of Eq. (3). This last term is like putting a cone on top of the highest contour meaning that it is not as precise as passing 10 more contours between the highest contour and the points above this contour but the results corroborate that the difference is around $0.06 \mathrm{~m}^{3}$ which is acceptable by most earthwork projects.

For a sensitivity analysis, let us consider volume of 1 cubic meter i.e., volume (V) is 1 in the following formula:

$\mathrm{V}=\mathrm{l} \mathrm{w} \mathrm{h}$ 
where $\mathrm{I}$ is the length, $\mathrm{w}$ is the width and $\mathrm{h}$ is the height, and they are all $1 \mathrm{~m}$. If we assume $3 \mathrm{~cm}$ error for length and width, and $3 \mathrm{~mm}$ error for height measurement, using error propagation law we get:

$$
\begin{aligned}
\sigma_{v}^{2} & =(w h)^{2} \sigma_{l}^{2}+(l h)^{2} \sigma_{w}^{2}+(l w)^{2} \sigma_{h}^{2} \\
\sigma_{v}^{2} & =1^{2} 0.03^{2}+1^{2} 0.03^{2}+1^{2} 0.003^{2} \\
\sigma_{v}^{2} & =0.001809 \\
\sigma_{v} & =0.043 \mathrm{~m}^{3}
\end{aligned}
$$

This result is very close to $0.06 \mathrm{~m}^{3}$ meaning that $0.06 \mathrm{~m}^{3}$ error is very close to the achievable error level.

\section{Conclusions}

In this paper, the precision of volume computations utilizing the contours method was compared against volume computations using the grids method and a TIN. If only the contour areas within the project area are considered without regard to the entire size of the project, the volume computations utilizing the contours method will yield very different results. Accurate determination of the volume moved is critical. Hence, for accurate volume computations using the contours method, a new formula is proposed, which yields very close results to the results of the grids method and a TIN.

\section{ACKNOWLEDGEMENTS}

First author thanks to Nick Barbella, Luz Garcia, Antonio Saldivar, Steve Sedgwick and Touko Vue for their help during field work.

\section{REFERENCES}

Crawford, W. G. 2008. Construction Surveying and Layout, $3^{\text {rd }}$ Edition, Indiana: Creative Construction Publishing Inc.

Wolf, P. R and Ghilani, C. D. 2006. Elementary Surveying, $11^{\text {th }}$ Edition, New Jersey: Pearson Prentice Hall.

Nathanson, J. Lanzafama, M. T. and Kissam, P. 2011. Surveying Fundamentals and Practices, New Jersey: Pearson Prentice Hall.

McCormac, J. Sarasua, W. and Davis, W. 2013. Surveying, $6^{\text {th }}$ Edition, New Jersey: John Wiley \& Sons Inc. 
Kavanagh, B. 2009. Surveying, Principles and Applications, $8^{\text {th }}$ Edition, New Jersey: Pearson Prentice Hall.

Kavanagh, B. 2010. Surveying with Construction Applications, $7^{\text {th }}$ Edition, New Jersey: Pearson Prentice Hall. 